\title{
Nutrition and migration: people on the move
}

\author{
BY ELIZABETH DOWLER \\ Centre for Human Nutrition, London School of Hygiene and Tropical Medicine, 2 Taviton Street, \\ London WCIH OBT
}

AND CLAUDIA MCCONNELL

Department of International Community Health, Liverpool School of Tropical Medicine, Pembroke Place, Liverpool L3 $5 Q A$

Following the success of the first workshop at Edinburgh the chairwomen had proposed an informal workshop on the important topic of nutrition and migration. One objective was to raise and discuss issues of concern to nutritionists who work with people facing acute food shortages. The other was to consider how best to determine the extent of, and appropriate response to, such crises. About fifty people took part and contributed views from different countries.

Nicola Ruck began with a review of the role of food aid in health and nutrition programmes. The disincentive effects of food aid, the need for detailed local level evaluation, the importance of integrating food into other aid flows and the inappropriateness of food aid for regular supplementary feeding programmes were described. Evidence that dairy food aid undermines breast-feeding practices was presented, and the need to distribute food amongst refugees in ways that do not increase dependency was stressed. Finally, recent research on food aid has emphasized the necessity of better measurements of nutritional need and effects of feeding programmes.

Elizabeth Dowler raised a number of issues by summarizing a recent report by Helen Young and Suzanne Jaspers which had been the focus of a meeting on the role of nutritional surveillance in famine at IDS, Sussex. The report reviewed the place of nutrition in understanding famine; the use of nutrition data in early-warning systems; and new approaches to nutritional surveillance. The main question arising from the report is whether continued nutritional surveillance can be justified when political constraints limit both the timely use of information and the choice of appropriate interventions.

Claudia McConnell summarized the uses of nutritional status information: to predict problems (early warning); to target interventions; to aid the management and monitoring of programmes; and to lobby for resources. The discussion included experiences of using such information in Guatemala, The Gambia, Nigeria, Ghana and Indonesia. It was suggested that mid-upper arm circumference in women could be a better (and more easily obtained) predictor of malnutrition than child weights. Food distribution at national and household levels was discussed. Questions were raised about whether donors are amenable to (and will act on) more appropriate local indicators of food need instead of the almost universal reliance on mortality.

Participants were keen that opportunities for these discussions should continue at future Nutrition Society meetings. The importance of a forum for ideas on actionoriented nutrition research related to economic development was stressed. Specific ideas for a workshop next year were: rapid assessment procedures, the relationship between 
poverty and nutrition, and follow-up to the International Conference on Nutrition in December. The need for a special interest group to serve these needs was also discussed. Interested members were asked to send ideas and/or contributions to Catherine Geissler, Department of Nutrition and Food Science, King's College, London. 